\title{
Lower-Molecular-Weight Chitosan-Treated Polyethyleneimine: a Practical Strategy For Gene Delivery to Mesenchymal Stem Cells
}

\author{
Minchen Liu ${ }^{\mathrm{a}} \quad$ Lu Zhang $^{\mathrm{b}, \mathrm{e}}$ Qingqing Zhao ${ }^{\mathrm{d}}$ Xinchi Jiang ${ }^{\mathrm{c}}$ Luyao $\mathrm{Wu}^{\mathrm{c}}$ \\ Yulan $\mathrm{Hu}^{\mathrm{b}}$ \\ aEngineering Research Center of Modern Preparation Technology of TCM, Innovation Research \\ Institute of Traditional Chinese Medicine, Shanghai University of Traditional Chinese Medicine, \\ Shanghai, 'Department of Cultural heritage and Museology, Zhejiang University, Hangzhou, Institute \\ of Pharmaceutics, College of Pharmaceutical Sciences, Zhejiang University, Hangzhou, ${ }^{\mathrm{d} C h o n g}$, Ining \\ Medical University, Chongqing, ${ }^{e}$ Research Institute of Traditional Chinese Medicine, Heilongjiang \\ University of Chinese Medicine, Haerbin, China
}

\section{Key Words}

Mesenchymal stem cells $•$ Gene delivery $\cdot$ Safety evaluation $\bullet$ Chitosan $\bullet$ Polyethylenimine

\begin{abstract}
Background/Aims: Genetic modification of mesenchymal stem cells (MSCs) is an essential requirement for their use as a delivery vehicle. To achieve higher transfection efficiency and better reproducibility than previously synthesized chitosan $(100 \mathrm{kDa})$-polyethylenimine (PEl; $1200 \mathrm{Da})$, we synthesized a low molecular weight PEI (1200 Da)-grafted chitosan (50 kDa) (CP). Methods: Safety of CP/DNA or PEI (25 kDa)/DNA was evaluated by an MTT assay using A549 cells or MSCs and a zebrafish embryo model. Effects of CP/DNA on the characteristics of MSCs were evaluated using flow cytometry. Additionally, a pGL3 plasmid was used to investigate the transfection efficiency of PEI (25 kDa), chitosan (100 kDa)-PEI (1200 Da), and $\mathrm{CP}$ with different N/P mass ratios on A549 cells and MSCs. Furthermore, CP/pGL3 was used to investigate the effect of serum on transfection, and intracellular transport was assessed by observing the intracellular location of DNA using laser scanning confocal microscopy. In addition, the effect of endocytosis on transfection efficiency was evaluated using A549 cells pre-treated with different inhibitors. Investigations related to analysis of transfection efficiency were all performed using the BCA protein assay to standardize the data. Furthermore, TGF- $\beta 1$ and CXCR4-expressing plasmids were applied to evaluate the gene transfer efficiency of CP, including its effects on the osteogenic differentiation and migratory ability of MSCs. Results: The safety evaluation demonstrated that CP/DNA had significantly lower toxicity than PEI (25 kDa)/DNA. Additionally, DNA entered MSCs transfected by CP without changing their properties, while the examination of intracellular transport demonstrated that CP/pGL3 was internalized rapidly into MSCs. Furthermore, studies of the internalization mechanism showed that $\mathrm{CP} / \mathrm{pGL3}$ complexes entered the cells through caveolae-mediated endocytosis, thereby
\end{abstract}

\begin{tabular}{ll}
\hline Yulan $\mathrm{Hu}$ & Department of Cultural heritage and Museology, Zhejiang University \\
& 148-Tian-Mu-Shan Road, Hangzhou 310028, Hangzhou (China) \\
& E-Mail hu_yulan@zju.edu.cn
\end{tabular}


Liu et al.: Gene Delivery to Mesenchymal Stem Cells by Lower-Molecular-Weight

Chitosan-Treated Polyethyleneimine

suggesting that the CP coating helped DNA enter A549 cells without the requirement for receptors. Compared to PEI $(25 \mathrm{kDa})$, the interference of serum on transfection was reduced significantly with the use of CP in both A549 cells and MSCs. To evaluate the effects of gene delivery using the constructed $\mathrm{CP}$ complex and the possibility of obtaining gene-engineered MSCs, TGF- $\beta 1$ - and CXCR4-expressing plasmids were successfully delivered into MSCs, confirming their ability to induce osteogenesis and change the migratory ability of MSCs, respectively. Conclusion: These results demonstrated that $\mathrm{CP}$ could be used to deliver genes into MSCs and could potentially be used in gene therapy based on MSCs.

\section{Introduction}

(c) 2018 The Author(s)

Published by S. Karger AG, Basel

The use of mesenchymal stem cells (MSCs) in tissue engineering and regenerative medicine has great potential because of their self-renewal ability, easy accessibility, and multi-lineage differentiation potential [1]. However, before being administered to a subject, MSCs must be expanded and genetically modified in vitro because its distribution in bone marrow is limited and would not provide a powerful therapeutic effect $[2,3]$.

Successful transfection of MSCs is largely dependent on the efficiency of the vehicle or vector used to deliver a gene with minimal toxicity [4]. Due to safety concerns over the use of viral vectors, non-viral vectors have received greater attention [5] and are now considered a substitute for viral vectors because of their potential advantages [6]. However, further efforts are required to improve their gene transfer ability [7], especially in MSCs. Among the nonviral DNA carriers, cationic polymers have an important position because they can form a complex with DNA through electrostatic interactions. Cationic polymers can be modified by adjusting the constituents of the monomer, chemically modifying the functional groups, or controlling the polymerization conditions. In addition, the composition of cationic polymers can be controlled by conjugation with a targeting ligand or intracellular trafficking enhancer [8].

Polyethylenimine (PEI; $25 \mathrm{kDa}$ ) has been shown to be the most effective vector because of its high $\mathrm{pH}$ buffering capacity [9]. Nevertheless, its non-degradable properties and high cytotoxicity have restricted its application. Although low molecular weight PEI has lower toxicity, its transfection efficiency was reduced [10]. It was reported that when low molecular weight PEI was combined with high molecular weight degradable linkers, new PEIs could be formed with a suitable molecular weight [11]. As such a linker, chitosan shows low cytotoxicity and high biocompatibility; however, it lacks charge and is insoluble at physiological $\mathrm{pH}$, which has limited its application in gene delivery [12]. Thus, chitosan (100 kDa)-PEI (1200 Da) was developed in our previous study [11]. However, the particle sizes of the chitosan (100 kDa)-PEI (1200 Da)/DNA complexes were not homogeneous, and its poor solubility in water hindered its application. Furthermore, compared to PEI ( $25 \mathrm{kDa}$ ), chitosan (100 kDa)-PEI (1200 Da) has no obvious advantage in providing sufficiently stable transfection efficiency in HeLa, HepG2, and A549 cell lines.

For the construction of a chitosan-PEI carrier with high transfection efficiency and low toxicity, Pimpha et al. prepared chitosan shell-PEI nanoparticles for gene delivery into MSCs [13]. The complex improved the level of gene transfection and extended the time period for expression in MSCs. However, the molecular weight of PEI (750 kDa) is still high and its potential toxicity cannot be ignored.

In the present study, a low molecular weight PEI (1200 Da)-introduced chitosan (50 $\mathrm{kDa}$ ( $\mathrm{CP}$ ) was constructed and characterized. CP had low toxicity in vitro and in vivo and high transfection efficiency in the presence and absence of serum, making it suitable for biological applications. CP/pGL3 entered the cells through caveolae-mediated endocytosis, which could be helpful for understanding the internalization mechanism of CP. In addition, the osteogenic differentiation properties of MSCs transfected with $\mathrm{CP} /$ transforming growth factor (TGF)- $\beta 1$ and the in vitro migration of MSCs transfected with $\mathrm{CP} / \mathrm{C}-\mathrm{X}-\mathrm{C}$ chemokine 


\section{Cellular Physiology Cell Physiol Biochem 2018;50:1255-1269 \begin{tabular}{l|l|l} 
and Biochemistry Published online: 25 October 2018 & $\begin{array}{l}\text { ○ } 2018 \text { The Author(s). Published by S. Karger AG, Basel } \\
\text { www.karger.com/cpb }\end{array}$ \\
\hline
\end{tabular}}

Liu et al.: Gene Delivery to Mesenchymal Stem Cells by Lower-Molecular-Weight

Chitosan-Treated Polyethyleneimine

receptor type 4 (CXCR4) were investigated. The findings of the present study are expected to lay the foundation for providing potential applications of $\mathrm{CP}$ in gene therapy based on the use of stem cells.

\section{Materials and Methods}

\section{Materials}

Chitosan (50 kDa, $100 \mathrm{kDa}$ ) was purchased from Yuhuan Biochemistry Co., Ltd. (Yuhuan, China). PEI (1200 Da, $25 \mathrm{kDa}$ ) was purchased from Aldrich Chemical Co., Ltd. (Milwaukee, WI). 1, 1'-Carbonyldiimidazole (CDI) was purchased from Pierce (Rockford, IL). 3-(4, 5-Dimethylthiazol-2-yl)-2, 5-diphenyltetrazolium bromide (MTT) was obtained from Sigma-Aldrich (St. Louis, MO). Fetal bovine serum (FBS), Dulbecco's modified Eagle's medium (DMEM), penicillin, streptomycin, and trypsin were purchased from Gibco BRL (Gaithersburg, MD). All other chemicals were of analytical grade. A pGL3 plasmid coding for luciferase was kindly provided by the Institute of Infectious Diseases, Zhejiang University. A TGF- $\beta 1$-expressing plasmid was purchased from OriGene Co. (Beijing, China). A CXCR4-expressing plasmid was kindly provided by the Department of Immunology, Juntendo University. A Luciferase Assay Kit and Bicinchoninic Acid (BCA) Protein Assay Kit were purchased from Beyotime Biotechnology Co., Ltd. (Shanghai, China).

\section{Animals}

Three-week-old male Sprague-Dawley rats (50-60 g) were supplied by the Experimental Animal Center, Zhejiang University, China. All animals were kept in a 12-h light/dark cycle at a temperature of $25 \pm$ $1{ }^{\circ} \mathrm{C}$ with free access to food and water. Zebrafish embryos were collected at 6 hours post fertilization (hpf) from the zebrafish aquarium in the Department of Pharmacy, Zhejiang University, and staged according to standard procedures [14]. All experimental procedures were carried out according to the guidelines of Zhejiang University for the welfare of experimental animals.

\section{Cell lines}

A549 (human lung carcinoma cell line) cells were obtained from the Institute of Biochemistry and Cell Biology, Shanghai Institutes for Biological Sciences, Chinese Academy of Sciences. Cells were cultured in DMEM (containing $10 \% \mathrm{FBS}$ ) at $37{ }^{\circ} \mathrm{C}$ and a humidified atmosphere containing $5 \% \mathrm{CO}_{2}$.

\section{Isolation and culture of MSCS}

MSCs were isolated from rat bone marrow cells obtained from the hind femurs of 3-week-old male Sprague-Dawley rats. The cell suspension was placed into a $100-\mathrm{mm}$ dish and cultured at $37{ }^{\circ} \mathrm{C}$ in a humidified atmosphere containing $5 \% \mathrm{CO}_{2}$. Second to sixth passage cells at sub-confluence were used for further study.

\section{Synthesis and characterization of CP}

$\mathrm{CP}$ was constructed as described previously with minor modifications [11]. Briefly, $1 \mathrm{~g}$ chitosan powder was dissolved in $50 \mathrm{~mL}$ of $0.5 \%$ acetic acid $(\mathrm{pH} \mathrm{7.0)}$, stirring overnight. CDI was added at a molar ratio of CDI:amine of chitosan = 2:1. PEI (1200 Da) was added dropwise at a molar ratio of PEI:amine of 3:1. Finally, the mixture was dialyzed for 3 days and freeze-dried. The composition of $\mathrm{CP}$ was evaluated by ${ }^{1} \mathrm{H}$ nuclear magnetic resonance $\left({ }^{1} \mathrm{H}\right.$ NMR) spectrometry (Avance ${ }^{\mathrm{TM}}$ 600; Bruker, Billerica, MA) and elemental analysis.

\section{Determination of buffering capacity}

The buffering ability of $\mathrm{CP}$ at the drop from $\mathrm{pH} 10.0$ to $\mathrm{pH} 2.0$ was determined, according to the method described by Wang et al. [15]. PEI (25 kDa) and CP were prepared with the pH raised to 10.0 by using $1 \mathrm{M}$ $\mathrm{NaOH}$ and were titrated with $0.1 \mathrm{~N} \mathrm{HCl}$. The volumes of $\mathrm{HCl}$ used were recorded, and $\mathrm{pH}$ was measured with a pH meter. 


\section{Cellular Physiology Cell Physiol Biochem 2018;50:1255-1269 \\ \begin{tabular}{l|l|l} 
and Biochemistry & $\begin{array}{l}\text { DOI: 10.1159/000494585 } \\
\text { Published online: 25 October } 2018\end{array}$ & $\begin{array}{l}\text { C) } 2018 \text { The Author(s). Published by S. Karger AG, Basel } \\
\text { www.karger.com/cpb }\end{array}$
\end{tabular}}

Liu et al.: Gene Delivery to Mesenchymal Stem Cells by Lower-Molecular-Weight

Chitosan-Treated Polyethyleneimine

\section{Characterization of CP/DNA complexes}

$\mathrm{CP} / \mathrm{DNA}$ was prepared by combining the CP solution with DNA and incubating at room temperature for 20 min with gentle vortexing. The morphology of CP/DNA complexes was observed under transmission electron microscopy (TEM; JEM-1200EX; JEOL, Tokyo, Japan). Particle sizes, zeta potential, and polydispersity index (PDI) were measured using a laser particle analyzer (Zetasizer 3000HS; Malvern Panalytical, Malvern, $\mathrm{UK}$ ) with different N/P mass ratios (for the calculation of N/P ratios, 330 Da was used as an average mass per charge for DNA). The effect of CP on DNA condensation (N/P mass ratios from 0.1 to 4 ) was investigated by electrophoresis on a $1 \%$ agarose gel in Tris-acetate buffer at $120 \mathrm{~V}$ for $40 \mathrm{~min}$, and viewed on an ultraviolet illuminator to visualize the DNA migration patterns.

\section{Cell viability assays}

Cytotoxicity of CP/DNA or PEI (25 kDa)/DNA was determined with an MTT assay. A549 cells or MSCs were seeded into 96-well plates at a density of $7.0 \times 10^{3}$ cells/well. After $24 \mathrm{~h}$, the medium was replaced with fresh medium. The cells were treated with $100 \mu \mathrm{L}$ sterile samples at a range of concentrations. After $48 \mathrm{~h}, 20 \mu \mathrm{L}$ MTT solution ( $5 \mathrm{mg} / \mathrm{mL}$ ) in phosphate-buffered saline was added to each well, and the plate was incubated for $4 \mathrm{~h}$. The supernatant was removed and $100 \mu \mathrm{L}$ DMSO was added to each well. After the formazan crystals had dissolved completely, optical density at $570 \mathrm{~nm}$ was determined with a model 680 Microplate Reader (Bio-Rad Laboratories, Inc., Hercules, CA).

\section{Safety evaluation using a zebrafish model}

For further safety evaluation in vivo, 20 healthy zebrafish embryos were transferred to a 24-well plate by adding $2 \mathrm{~mL}$ zebrafish culture medium. Different concentrations of CP/DNA or PEI (25 kDa)/DNA were added to the wells for $96 \mathrm{~h}$ at $28.5^{\circ} \mathrm{C}$. To evaluate the toxicity of CP/DNA and PEI (25 kDa)/DNA, the hatching rate of zebrafish embryos at $96 \mathrm{hpf}$ was observed under a stereo microscope (Nanjing Jiangnan Novel Optics Co. Ltd., Nanjing, China).

\section{Effect of CP/DNA complexes on the characteristics of MSCS}

The effect of CP/DNA complexes on the characteristics of MSCs was evaluated using surface markers before and after transfection. Surface antigen markers of MSCs were identified using flow cytometry (FC500MCL; Beckman Coulter, Munich, Germany). Cells were detached using trypsin/EDTA, and incubated with the isotype control and specific antibodies, namely, anti-CD34-PerCP (Santa Cruz Biotechnology, Dallas, TX), anti-CD45-PE (BioLegend, San Diego, CA), and anti-CD90-FITC (BioLegend) for $30 \mathrm{~min}$ at $4{ }^{\circ} \mathrm{C}$.

\section{Transfection efficiency of the vectors}

The pGL3 vector (encoding luciferase) was used to investigate the transfection efficiency of PEI (25 $\mathrm{kDa}$ ), chitosan (100 kDa)-PEI (1200 Da), and CP with different N/P mass ratios in A549 cells and MSCs. Luciferase assay was carried out according to the manufacturer's instructions (Promega, Madison, WI). Light units (LU) due to luciferase activity were measured using a chemiluminometer (Autolumat LB953; EG\&G Berthold, Bad Wildbad, Germany). The results are expressed as relative LU (RLU)/mg cell protein as determined by the BCA protein assay.

\section{Effect of serum on the transfection of CP}

To investigate the effect of serum on the transfection of CP/pGL3, A549 cells or MSCs were seeded on 24 -well plates $\left(37^{\circ} \mathrm{C} ; 5 \% \mathrm{CO}_{2} ; 4 \mathrm{~h}\right)$. The medium was replaced with fresh medium with or without $10 \% \mathrm{FBS}$ containing $40 \mu \mathrm{L} \mathrm{CP} / \mathrm{pGL} 3$ or PEI $(25 \mathrm{kDa}) / \mathrm{pGL} 3$. After $24 \mathrm{~h}$, the samples were removed and the cells were incubated in complete medium. Results are expressed as RLU/mg cell protein as determined by the BCA protein assay.

\section{Intracellular transport of $C P / D N A$}

The pGL3 vector was labeled by a Label IT Tracker Fluorescein Labeling Kit (Mirus, Madison, WI) according to the manufacturer's instructions. MSCs (approximately $1.0 \times 10^{4}$ cells) were cultured in 15-mm glass bottom cell culture dishes. After $24 \mathrm{~h}$, CP/fluorescein-DNA was added to the cells with Opti-MEM. Lysosomes in the transfected cells were labeled by LysoTracker Red (Beyotime). Before being fixed with 


\section{Cellular Physiology Cell Physiol Biochem 2018;50:1255-1269

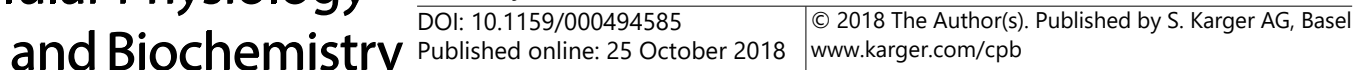

Liu et al.: Gene Delivery to Mesenchymal Stem Cells by Lower-Molecular-Weight

Chitosan-Treated Polyethyleneimine

paraformaldehyde and stained with 4'-6-diamidino-2-phenylindole, MSCs were treated with CP/DNA for $0.5,1,2,4$, and $6 \mathrm{~h}$. The intracellular location of DNA was observed under a laser scanning confocal microscope (IX81-FV1000; Olympus, Tokyo, Japan).

\section{Endocytosis-dependency of cellular uptake}

The effect of endocytosis on transfection efficiency was evaluated in A549 cells pre-treated with different inhibitors, as follows: 1) to inhibit the clathrin-mediated endocytosis pathway, $5 \mu \mathrm{g} / \mathrm{mL}$ chlorpromazine (CPZ) was used for $0.5 \mathrm{~h}[16,17]$; 2) to inhibit caveolae-mediated endocytosis, $10 \mathrm{mM}$ methyl- $\beta$-cyclodextrin (M $\beta C D$ ) was used for $0.5 \mathrm{~h}$; and 3) to inhibit macropinocytosis in the culture medium pathway, $20 \mathrm{mM}$ amiloride was used for $15 \mathrm{~min}[18,19]$. The cells were incubated at $37^{\circ} \mathrm{C}$ with $\mathrm{CP} / \mathrm{pGL3}$ for $4 \mathrm{~h}$ with these inhibitors. Subsequently, the medium was replaced with DMEM containing 10\% FBS, 1\% L-glutamine, streptomycin $(50 \mathrm{U} / \mathrm{mL})$, and penicillin $(50 \mathrm{U} / \mathrm{mL})$. The results are expressed as RLU/mg cell protein as determined by the BCA protein assay.

\section{ALP activity assay and calcium node staining}

MSCs were seeded on 24-well microplates at a density of $5.0 \times 10^{4}$ cells/well. After $24 \mathrm{~h}$, the medium was replaced with DMEM containing $40 \mu \mathrm{L}$ CP or CP/TGF- $\beta 1$ for $4 \mathrm{~h}$. After 14 days, MSCs and MSCs treated with $\mathrm{CP}$ or $\mathrm{CP} / \mathrm{TGF}-\beta 1$ were lysed and centrifuged at $12,000 \times g$ for $10 \mathrm{~min}$. The supernatant was removed to measure ALP activity according to the manufacturer's instructions. MSCs and MSCs treated with CP or $\mathrm{CP} / \mathrm{TGF}-\beta 1$ were stained with $2 \%$ alizarin red solution for calcium node staining.

\section{CXCR4 expression}

To study the transfection efficiency of CP, we transferred the polymer/CXCR4 linked with enhanced green fluorescent protein (EGFP) into MSCs. MSCs were seeded on 24-well plates at a density of $1.0 \times 10^{5}$ cells/well. After $24 \mathrm{~h}$, each well received $1 \mu \mathrm{g}$ CXCR4 plasmid in the absence of CP. CP/CXCR4 was diluted in $500 \mu \mathrm{L}$ Opti-MEM medium for $4 \mathrm{~h}$ at $37^{\circ} \mathrm{C}$. The Opti-MEM medium was replaced with DMEM containing $10 \%$ FBS, and cultured for $24 \mathrm{~h}$. Green fluorescence was observed under a fluorescence microscope.

\section{In vitro migration of MSCS}

The migratory ability of MSCs and MSCs treated with CXCR4 was determined using Transwell plates (Costar, Corning, CA) that were $6.5 \mathrm{~mm}$ in diameter with $8-\mu \mathrm{m}$ pore membranes. The cells $\left(4.0 \times 10^{5}\right.$ cells/ $\mathrm{mL}$ ) were added to the upper chamber. DMEM with 10\% FBS or B16F10 cells was added to the lower well of the Transwell plate and cultured at $37^{\circ} \mathrm{C}$ overnight. Then, the MSCs on the upper side of the membrane were wiped off, and the migrated MSCs were stained using crystal violet.

\section{Statistical analysis}

All experiments were repeated three times, and the results are expressed as the mean and standard deviation. Statistical analyses were performed using non-parametric test. A p value $<0.05$ was considered statistically significant.

\section{Results}

\section{Synthesis and characterization of CP}

The composition of CP was estimated by ${ }^{1} \mathrm{H}$ NMR (Fig. 1A) and elemental analysis (Fig. 1B). According to ${ }^{1} \mathrm{H} \mathrm{NMR}$, the proton peak area of $\mathrm{CP}$ at $\delta=3.0$ to $2.5 \mathrm{ppm}$ was largely increased, which indicated that PEI (1200 Da) had been linked with the chitosan (50 kDa) chain. Elemental analysis demonstrated that the nitrogen content of CP was increased compared to chitosan. Therefore, CP was considered to be successfully synthesized. The buffering capacity of the vector should not be negligible for molecules escaping from the endosomes of cells [20]. Fig. 1C shows that CP had a similar buffering capacity as PEI (25 $\mathrm{kDa}$ ). This shows that CP was suitable for gene transfection. 
Liu et al.: Gene Delivery to Mesenchymal Stem Cells by Lower-Molecular-Weight

Chitosan-Treated Polyethyleneimine

Characterization of CP/DNA complexes

TEM demonstrated the regular spherical morphology of CP (Fig. 1D). The particle size was $215 \mathrm{~nm}$ when the $\mathrm{N} / \mathrm{P}$ mass ratio was 1 (Fig. 1E). However, at a mass ratio $>2$, the complexes were approximately $\quad 100$ $\mathrm{nm}$ in size. When the $\mathrm{N} / \mathrm{P}$ mass ratio was 1 , the zeta potential was negative, as the complex could not form completely. When the N/P mass ratio was increased, the zeta potential of the copolymer increased rapidly to positive values, which is consistent with previous reports [21]. Thus, at a high $\mathrm{N} / \mathrm{P}$ mass ratio, net electrostatic repulsive forces could prevent aggregation among the complexes. Fig. 1E shows the unsuitable PDI of CP/DNA as the $\mathrm{N} / \mathrm{P}$ mass ratio increased, revealing that the appropriate $\mathrm{N} / \mathrm{P}$ mass ratio should

be in the range of 2.5-5. When the N/P mass ratio was 2-4, DNA migration was retarded completely (Fig. 1F), indicating that DNA was bound with CP tightly and completely, so little DNA escaped in this N/P mass ratio range. According to previous studies, CP/DNA has low cytotoxicity and high transfection efficiency in MSCs at an N/P mass ratio of 3 [22]. Therefore, $\mathrm{CP} / \mathrm{DNA}$ could form the most appropriate positive potential nanoparticles at this ratio (N/P $=3$ ), which was used in the following safety and flow cytometry analyses.

\section{Safety evaluation of non-viral vectors}

Fig. 2A-2D shows the cytotoxicity of the copolymer in A549 cells and MSCs. The cytotoxicity of the CP was apparently lower than that of PEI (25 kDa) in A549 cells and MSCs (Fig. 2A and 2C). A similar result was obtained in the comparison of PEI (25 kDa)/DNA and CP/DNA (Fig. 2B and 2D). Furthermore, safety was evaluated in vivo by using a zebrafish embryo model. The protocol for this experiment is described in Fig. 2E. Zebrafish embryos were exposed to CP/DNA or PEI (25 kDa)/DNA for $96 \mathrm{~h}$. The results showed that embryo hatching was inhibited in a dose-dependent manner by CP/DNA or PEI (25 kDa)/DNA. The hatching rate of the CP/DNA group at $96 \mathrm{hpf}$ was apparently increased in comparison with 
Liu et al.: Gene Delivery to Mesenchymal Stem Cells by Lower-Molecular-Weight Chitosan-Treated Polyethyleneimine
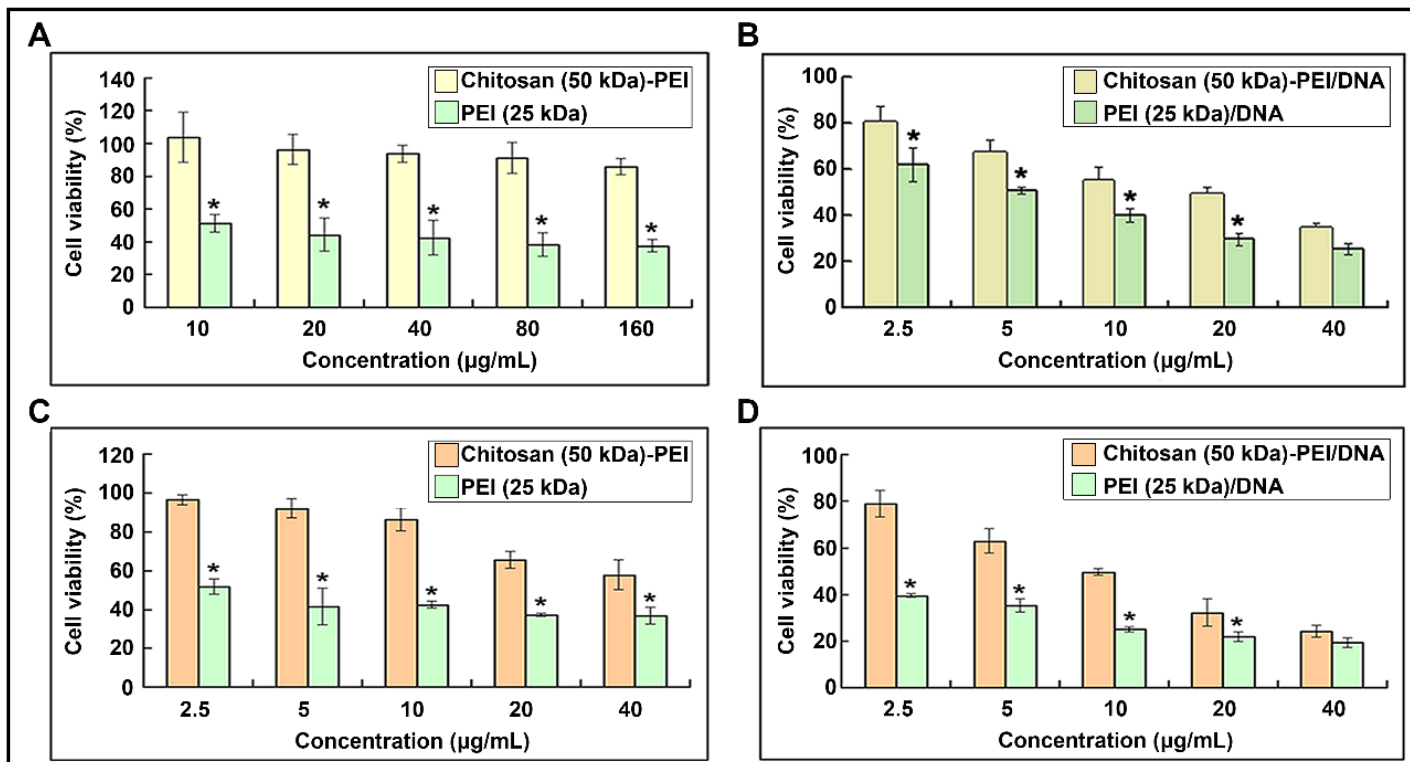

E

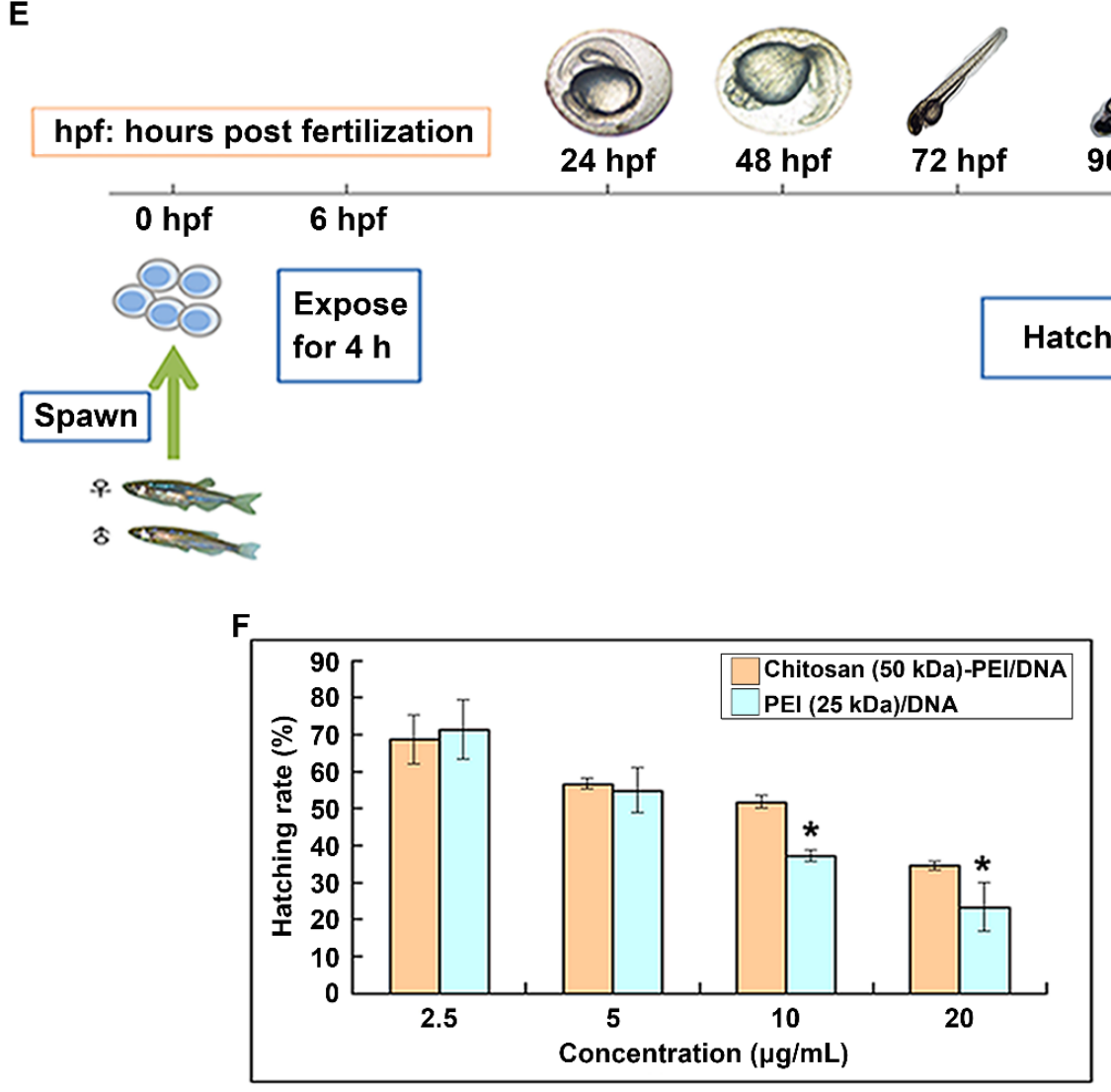

Fig. 2. In vitro cytotoxicity of the copolymer (A) and copolymer/DNA (B) analyzed by the MTT assay in A549 cells at $48 \mathrm{~h}$. In vitro cytotoxicity of the copolymer (C) and copolymer/DNA (D) analyzed by the MTT assay in MSCs at $48 \mathrm{~h}$. (E) The protocol for the evaluation of safety using a zebrafish model. (F) The hatching rate of zebrafish embryos exposed to CP/DNA or PEI (25 kDa)/DNA at 96 hpf. Notes: ${ }^{*}$ P<0.05: PEI (25 kDa) group vs. CP group or PEI (25 kDa)/DNA group vs. CP/DNA group. 


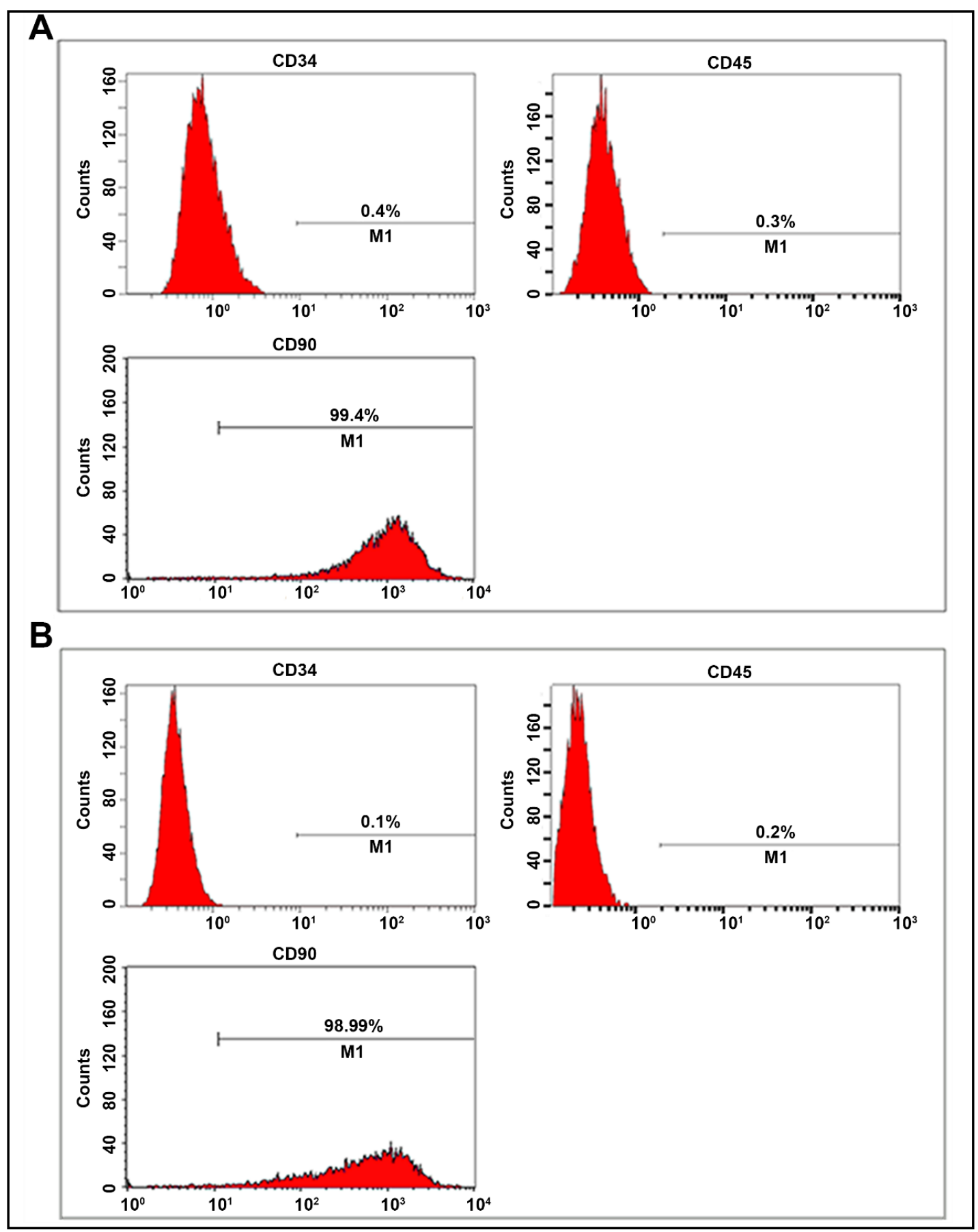

Fig. 3. MSC surface antigen markers identified with flow cytometric analysis before (A) and after (B) CP/ DNA transfection.

the PEI (25 kDa)/DNA group (Fig. 2F), especially at the higher concentrations of 10 and 20 $\mu \mathrm{g} / \mathrm{mL}$, which provides a reference for the safety evaluation of CP.

\section{Effect of CP/DNA complexes on the characteristics of MSCs}

The MSCs expressed the surface antigen CD90, but not CD34 or CD45, both before and after transfection with CP/DNA (Fig. 3A and 3B). The level of purity obtained was sufficient because greater than $95 \%$ of MSCs were positive for this marker. Therefore, the expression of MSC surface markers was not significantly influenced after transfection with CP/DNA. 

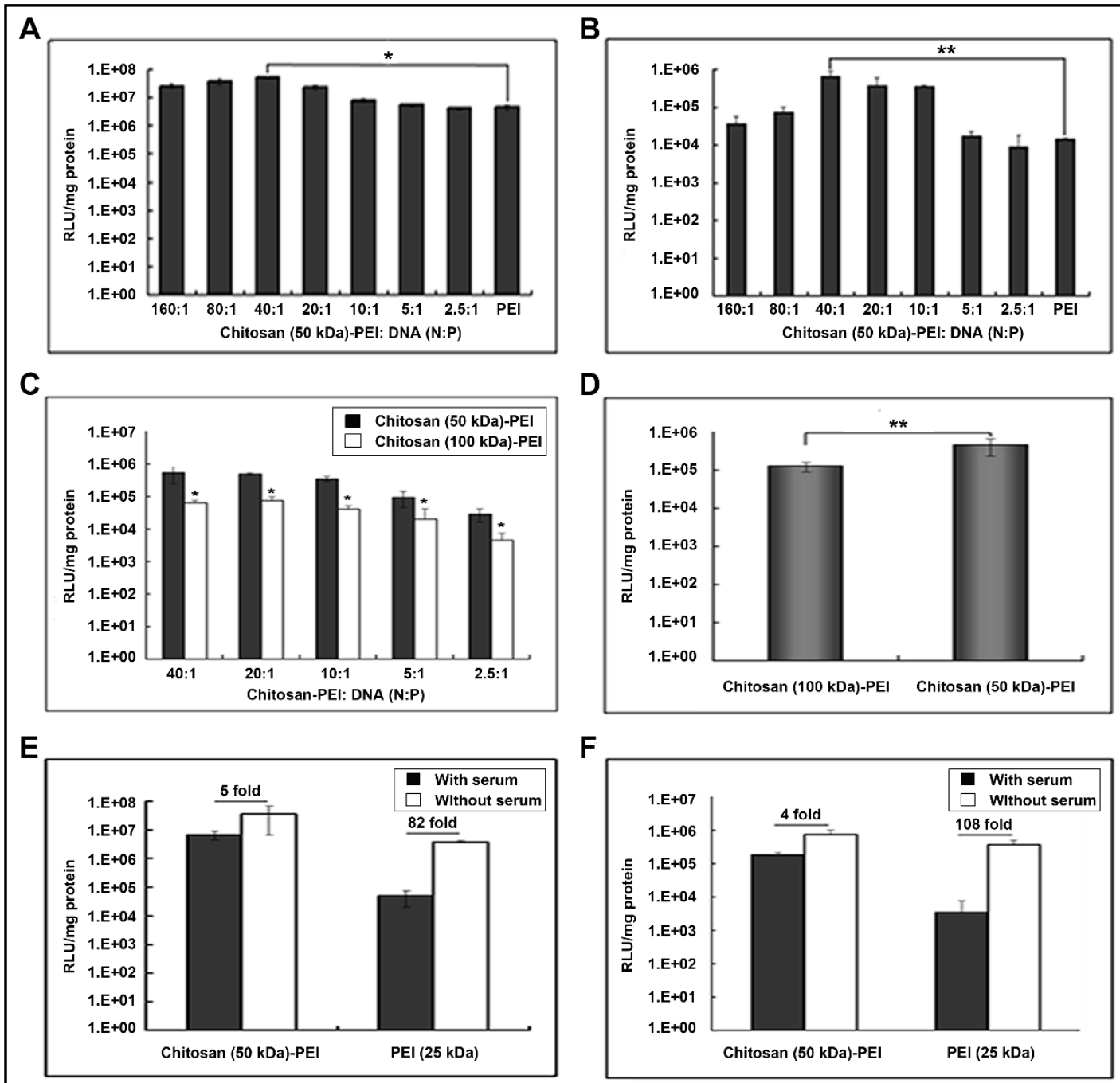

Fig. 4. Transfection efficiency of CP/pGL3 with the N/P mass ratio varying from 2.5:1 to 160:1 in A549 cells (C) and MSCs (D), while PEI (25 kDa)/pGL3 was used as a positive control. (E) The transfection efficiency of $\mathrm{CP} / \mathrm{pGL} 3$ was investigated and compared with chitosan (100 kDa)-PEI (1200 Da)/pGL3 with the N/P mass ratio varying from 2.5:1 to 40:1 in A549 cells. (F) The transfection efficiency of CP/pGL3 was investigated and compared with chitosan (100 kDa)-PEI (1200 Da)/pGL3 with an N/P mass ratio of 40 in MSCs. The effect of serum on the transfection of CP/pGL3 in A549 cells (G) and MSCs (H) compared with PEI (25 kDa)/ pGL3.Notes: "P<0.05: PEI ( $25 \mathrm{kDa}$ )/DNA group vs. CP/DNA group with an N/P mass ratio of 40 in A549 cells or chitosan (100 kDa)-PEI (1200 Da)/DNA group vs. CP/DNA group with the N/P mass ratio varying from 2.5:1 to 40:1 in A549 cells; **P<0.01: PEI (25 kDa)/DNA or chitosan (100 kDa)-PEI (1200 Da)/DNA group vs. CP/DNA group with an N/P mass ratio of 40 in MSCs.

\section{Transfection efficiency of the vectors}

In order to search for the optimum transfection efficiency of CP/pGL3 by adjusting the N/P mass ratio from 2.5:1 to 160:1, we transferred the complex into A549 cells and MSCs, while PEI ( $25 \mathrm{kDa}$ ) was used as control. When the N/P mass ratio reached 5 , the transfection efficiency of the complex was similar to that of PEI (25 kDa) in both A549 cells and MSCs (Fig. 4A and 4B). When it reached 40, transfection efficiency was enhanced significantly in comparison with PEI (25 kDa). A better transfection efficiency of CP was observed in A549 cells, with the N/P mass ratio varying from 2.5:1 to 40:1 (Fig. 4C). When the N/P mass ratio 


\section{Cellular Physiology \begin{tabular}{ll|l} 
and Biochemistry Published online: 25 October 2018 & $\begin{array}{l}\text { (c) } 2018 \text { The Author(s). Published by S. Karger AG, Basel } \\
\text { www.karger.com/cpb }\end{array}$
\end{tabular} \\ Liu et al.: Gene Delivery to Mesenchymal Stem Cells by Lower-Molecular-Weight Chitosan-Treated Polyethyleneimine}

reached 40 , the transfection efficiency of $\mathrm{CP}$ was higher than that of chitosan (100 kDa)PEI (1200 Da) in MSCs (Fig. 4D). Thus, this $\mathrm{N} / \mathrm{P}$ mass ratio was applied to the luciferase assay, the further study of the intracellular transport of $\mathrm{CP}$, and the evaluation of gene delivery efficiency based on CP/TGF- $\beta 1$ and CP/CXCR4.

\section{Effect of serum on the transfection of CP}

$\mathrm{CP}$ induced a slight decrease in pGL3 expression in A549 cells and MSCs, while there was a significant decrease in pGL3 expression in all culture models transfected by PEI (25 kDa) (Fig. 4E and 4F). These results demonstrated that in the presence of serum, the intracellular uptake of PEI (25 $\mathrm{kDa}$ ) could be inhibited, but such interference was reduced by CP in A549 cells and MSCs.

\section{Intracellular transport of $C P / D N A$ complexes}

The intracellular process that CP/DNA undergoes in MSCs was observed by laser confocal fluorescence microscopy. pGL3 was labeled with fluorescein, and lysosomes were labeled with lysosome tracker probes, which can label acidic organelles in live cells at nanomolar concentrations. Recently, LysoTracker has been applied widely in intracellular mechanistic studies [23-25]. Fig. 5A demonstrates the time-dependent changes in CP/DNA complex internalization. After incubation for $1 \mathrm{~h}$, the fluoresceinDNA (green substance) was entrapped in lysosomes (red vesicles) and began to cluster around the nucleus (blue), while the majority of DNA successfully clustered near the nucleus after incubation for $4 \mathrm{~h}$, which demonstrated that CP/DNA was internalized rapidly into MSCs. In contrast, PEI (25 kDa) escapes from endosomes and enters the nucleus more quickly, whereas the DNA carried by chitosan barely enters the nucleus [26, 27]. Therefore, the time required and ability to escape from endosomes and enter the nucleus are very important for both the cytotoxicity and transfection efficiency of vectors. CP escaped from endosomes at a proper combination rate, which enhanced its transfection efficiency, while cytotoxicity was not increased.

\section{Internalization mechanisms of CP}

To investigate further the internalization mechanisms of the vector, CP/pGL3 endocytosis in A549 cells was analyzed in the presence of endocytosis inhibitors. In Fig. 5B, DNA internalization was inhibited by MBCD (a lipid-raft inhibitor), but not by CPZ (a clathrinmediated endocytosis inhibitor) or amiloride (a macropinocytosis-mediated endocytosis inhibitor). Therefore, $C P / D N A$ internalization was only inhibited by $M \beta C D$, which selectively extracts cholesterol to organize sphingolipid rafts and has a very close relationship with caveolae-mediated and macropinocytosis-mediated endocytosis [28]. The internalization 
Liu et al:: Gene Delivery to Mesenchymal Stem Cells by Lower-Molecular-Weight

Chitosan-Treated Polyethyleneimine

of CP/DNA was inhibited by $\mathrm{M} \beta C D$, but not completely by amiloride, which demonstrated that $\mathrm{CP} /$ DNA entered the cells through caveolae-mediated endocytosis. The clathrinmediated endocytosis inhibitor CPZ mainly affects receptor-mediated endocytosis [29]. These results indicated that $\mathrm{CP}$ could help DNA enter A549 cells without utilizing receptors.

ALP activity assay and calcium node staining Alizarin red staining demonstrated that the cells formed aggregates or nodules (Fig. 6A). Meanwhile, the osteogenic differentiation of MSCs transfected with CP/ TGF- $\beta 1$ was evaluated by ALP activity. ALP is

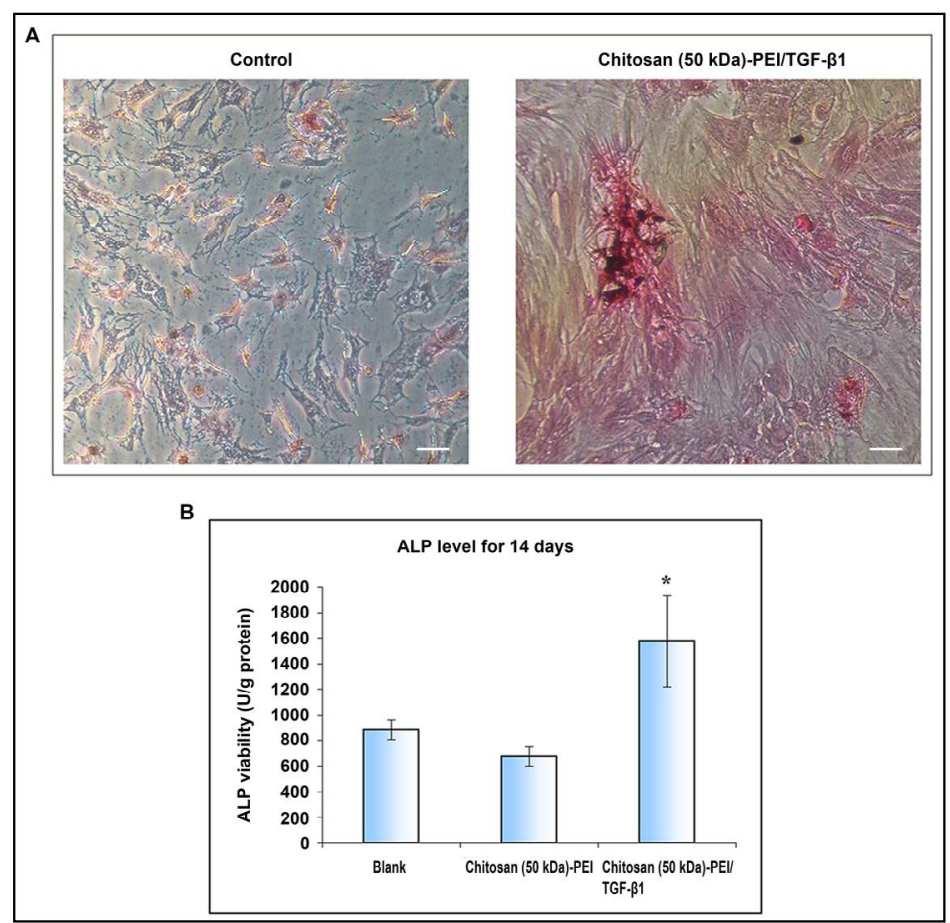

Fig. 6. Effects of CP/TGF- $\beta 1$ on osteogenic differentiation of MSCs. (A) Calcium node staining. Scale bar $=100 \mu \mathrm{m}$. (B) ALP level of MSCs cultured with CP/TGF- $\beta 1$ for 14 days.Notes: ${ }^{*} \mathrm{P}<0.05$ : CP/TGF- $\beta 1$ group vs. blank or CP group. an early mineralization-

related protein marker for osteogenesis in MSCs. After 14 days of induction, ALP activity was significantly increased by transfection with CP/TGF- $\beta 1$ compared to that in naïve MSCs (Fig. 6B). These findings indicated that MSCs transfected with CP/TGF- $\beta 1$ successfully differentiated into osteoblasts.

\section{CXCR4 expression}

CXCR4 linked with EGFP was delivered to MSCs to assess the transfection efficiency of CP. After $24 \mathrm{~h}$ incubation, green fluorescence intensity was clearly increased in MSCs transfected with CP/CXCR4 compared to MSCs (Fig. 7A and 7B), indicating that CP transfected CXCR4 into MSCs efficiently.

\section{In vitro migration of MSCs}

CXCR4 overexpression was applied to increase the homing ability of systemically delivered MSCs toward 10\% FBS or B16F10 cells. The in vitro migration of MSCs-CXCR4 and MSCs was investigated (Fig. 7C), which confirmed that MSCs overexpressing CXCR4 have better tropism than naïve MSCs toward 10\% FBS or B16F10 cells. Moreover, it was demonstrated that CXCR4 could be transfected into MSCs efficiently by CP. 


\section{Cellular Physiology}

\begin{tabular}{l|l} 
and Biochemistry Published online: 25 October 2018 & $\begin{array}{l}\text { (c) } 2018 \text { The Author(s). Published by S. Karger AG, Basel } \\
\text { www.karger.com/cpb }\end{array}$
\end{tabular}

Liu et al.: Gene Delivery to Mesenchymal Stem Cells by Lower-Molecular-Weight Chitosan-Treated Polyethyleneimine

\section{Discussion}

Polymer aggregation on cell surfaces potentially leads to the cytotoxicity of PEI, which would impair important membrane functions. Besides, the high positive charge of the polymer can damage the cell membrane. The cationic polymers may disturb critical intracellular processes. Particularly, the primary amine could disrupt the function of protein kinase $\mathrm{C}$ by disturbing its kinase activity [30, 31]. Furthermore, high molecular weight PEI is significantly more toxic than low molecular weight PEI $[32,33]$. Therefore, we chose low molecular weight PEI (1200 Da) and degradable chitosan to synthesize the copolymers. The zebrafish embryo model was applied to investigate whether $\mathrm{CP}$ influenced embryonic development. The use of zebrafish has grown in popularity as an in vivo model for the screening of nanobiomaterials [34]. The value

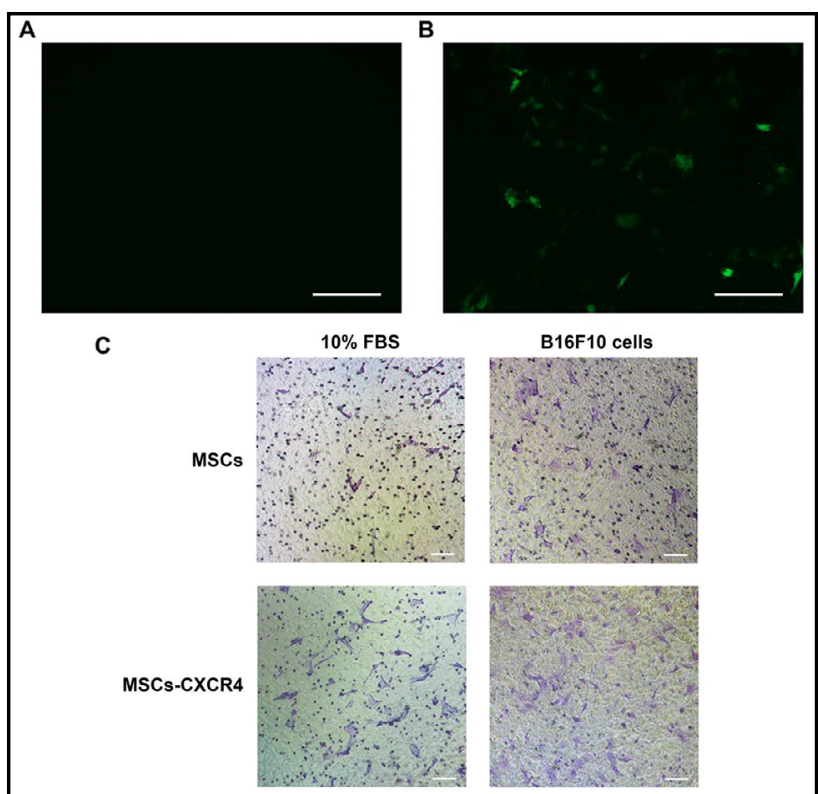

Fig. 7. CXCR4 linked with EGFP was used to examine CXCR4 expression in MSCs before (A) and after (B) CP/CXCR4 transfection. After $24 \mathrm{~h}$ incubation, green fluorescence was observed under a fluorescence microscope. Scale bar $=200$ $\mu \mathrm{m}$. (C) The migratory ability of MSCs was determined using Transwell plates before and after being transfected with $\mathrm{CP} /$ CXCR4. Scale bar $=100 \mu \mathrm{m}$. of this model relies on its biological similarity with more complex organisms, the fact that its genome shares more than $70 \%$ of genes with humans, and its high fecundity [35-37]._ENREF_45Nowadays, using zebrafish embryos to test the toxicity of nanoparticles has been highlighted in several studies [3840]. Our evaluation of safety in vitro and in vivo laid the foundation for the use of CP/DNA complexes for gene delivery to MSCs.

Under the interference of serum, the transfection efficiency of most cationic polymers is decreased, because of the presence of negatively charged serum proteins that combine competitively with polycations to decrease the combination of cationic polymers with DNA [41]. Although PEI ( $25 \mathrm{kDa}$ ) could be the most effective non-viral vector because of its high $\mathrm{pH}$ buffering capacity [9], its high cytotoxicity and non-degradable properties have hampered its application. Furthermore, its high positive charge combines with negatively charged serum proteins and decreases transfection efficiency. When considering the advantages of PEI and chitosan, both have a very low molecular weight, lack charge, and have low cytotoxicity [12, 32, 33], CP has similar buffering capacity as PEI (25 kDa) (Fig. 1C), while it has a lower positive charge. These factors could reduce the interference of serum on the transfection ability of CP.

MSCs are multipotent cells that can be induced to differentiate along many tissue-specific pathways, including bone (osteoblasts), fat cells (adipocytes), and cartilage (chondrocytes) [42]. However, before being administered to a subject, MSCs must be expanded and genetically modified in vitro, because only a few MSCs are found in bone marrow and would not provide a powerful therapeutic effect [3]. Therefore, the application of gene therapy largely depends on the efficacy of gene transfection into MSCs. To evaluate the efficiency of gene delivery using CP and the feasibility of obtaining gene-engineered MSCs, TGF- $\beta 1$ - and CXCR4-expressing plasmids were successfully delivered into MSCs, confirming their ability to induce osteogenesis and change the migratory ability of MSCs, respectively. TGF- $\beta 1$ is a growth factor that plays an important role in the osteogenic differentiation of MSCs [43]. 


\section{Cellular Physiology Cell Physiol Biochem 2018;50:1255-1269

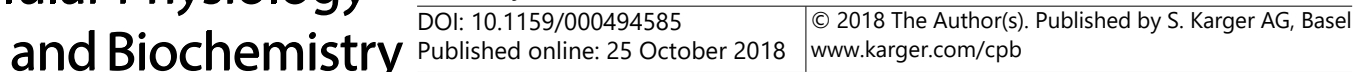 \\ Liu et al.: Gene Delivery to Mesenchymal Stem Cells by Lower-Molecular-Weight \\ Chitosan-Treated Polyethyleneimine}

MSCs transfected with CP/TGF- $\beta 1$ successfully differentiated into osteoblasts (Fig. 6). Furthermore, CXCR4 overexpression was used to enhance the homing ability of MSCs. CXCR4 and its ligand, SDF-1, have been studied widely in MSC migration because they are expressed in a large number of cells and tissues [44]. Many studies have demonstrated that the SDF-1/ CXCR4 axis plays an important role in stem cells $[45,46]$. Besides, it has been reported that CXCR4 modification does not influence the proliferation or phenotype of MSCs [47]. Similar to naïve MSCs, MSCs transfected with CXCR4 have a typical fibroblast-like structure, and their viability and proliferation do not change after being cultured for 6 days [48]. Above all, the successful transfection of two plasmids confirmed the potential of CP for gene therapy based on MSCs.

\section{Conclusion}

Chitosan (50 kDa)-PEI (1200 Da) (CP) was synthesized, and its structure, nitrogen content, and buffering capacity were characterized. CP/DNA showed much lower toxicity than PEI/DNA in both A549 and MSC culture models as well as in a zebrafish embryo model, and the CP/DNA complex did not change the properties of MSCs. CP/pGL3 exhibited a higher transfection efficiency than PEI/pGL3 in both A549 cells and MSCs, while the interference of serum was reduced significantly. Investigation of its intracellular transport demonstrated that $\mathrm{CP} / \mathrm{pGL} 3$ was internalized rapidly into MSCs. Internalization mechanism studies showed that $\mathrm{CP} / \mathrm{pGL} 3$ complexes entered the cells through caveolae-mediated endocytosis. Moreover, MSCs transfected with CP/TGF- $\beta 1$ successfully differentiated into osteoblasts, as demonstrated by both ALP activity and mineralization. Furthermore, the in vitro migration of MSCs expressing CXCR4 demonstrated better tropism than naïve MSCs. These results indicated that CP could be used to import genes into MSCs and could potentially be used in gene therapy based on stem cells.

\section{Acknowledgements}

This work was financially supported by National Natural Science Foundation of China (81472818) and by the Fundamental Research Funds for the Central Universities (Yu-Lan $\mathrm{Hu}$ ) and by Xinglin Young Talent Program of Shanghai University of Traditional Chinese Medicine. We would like to thank Dr. Hideo Yagita (Department of Immunology, Juntendo University) for providing CXCR4 plasmid.

\section{Disclosure Statement}

The authors declare no conflict of interests.

\section{References}

$\checkmark 1$ Chung C, Burdick JA: Influence of three-dimensional hyaluronic acid microenvironments on mesenchymal stem cell chondrogenesis. Tissue Eng Part A 2009;15:243-254.

$\checkmark 2$ He CX, Li N, Hu YL, Zhu XM, Li HJ, Han M, Miao PH, Hu ZJ, Wang G, Liang WQ, Tabata Y, Gao JQ: Effective gene delivery to mesenchymal stem cells based on the reverse transfection and three-dimensional cell culture system. Pharm Res 2011;28:1577-1590.

-3 Okazaki A, Jo J, Tabata Y: A reverse transfection technology to genetically engineer adult stem cells. Tissue Eng 2007;13:245-251.

4 Li S, Huang L: Nonviral gene therapy: promises and challenges. Gene Ther 2000;7:31-34. 


\section{Cellular Physiology Cell Physiol Biochem 2018;50:1255-1269 \begin{tabular}{l|l|l|l|l}
\hline DOI: 10.1159/000494585 & 2018 The Author(s). Published by S. Karger AG, Basel
\end{tabular} and Biochemistry

Chitosan-Treated Polyethyleneimine

-5 Park JS, Na K, Woo DG, Yang HN, Kim JM, Kim JH, Chung HM, Park KH: Non-viral gene delivery of DNA polyplexed with nanoparticles transfected into human mesenchymal stem cells. Biomaterials 2010;31:124132.

6 Leong KW, Mao HQ, Truong-Le VL, Roy K, Walsh SM, August JT: DNA-polycation nanospheres as non-viral gene delivery vehicles. J Control Release 1998;53:183-193.

7 Morille M, Passirani C, Vonarbourg A, Clavreul A, Benoit JP: Progress in developing cationic vectors for nonviral systemic gene therapy against cancer. Biomaterials 2008;29:3477-3496.

8 Schaffert D, Wagner E: Gene therapy progress and prospects: synthetic polymer-based systems. Gene Ther 2008;15:1131-1138.

-9 Kichler A, Leborgne C, Danos O: Dilution of reporter gene with stuffer DNA does not alter the transfection efficiency of polyethylenimines. J Gene Med 2005;7:1459-1467.

10 Wen Y, Pan S, Luo X, Zhang X, Zhang W, Feng M: A biodegradable low molecular weight polyethylenimine derivative as low toxicity and efficient gene vector. Bioconjug Chem 2009;20:322-332.

11 Gao JQ Zhao QQ, Lv TF, Shuai WP, Zhou J, Tang GP, Liang WQ, Tabata Y, Hu YL: Gene-carried chitosan-linkedPEI induced high gene transfection efficiency with low toxicity and significant tumor-suppressive activity. Int J Pharm 2010;387:286-294.

12 Lai WF, Lin MC: Nucleic acid delivery with chitosan and its derivatives. J Control Release 2009;134:158168.

13 Pimpha N, Sunintaboon P, Inphonlek S, Tabata Y: Gene delivery efficacy of polyethyleneimine-introduced chitosan shell/poly(methyl methacrylate) core nanoparticles for rat mesenchymal stem cells. J Biomater Sci Polym Ed 2010;21:205-223.

$>14$ Vlassov AV, Magdaleno S, Setterquist R, Conrad R: Exosomes: current knowledge of their composition, biological functions, and diagnostic and therapeutic potentials. Biochim Biophys Acta 2012;1820:940-948.

-15 Wang DA, Narang AS, Kotb M, Gaber AO, Miller DD, Kim SW, Mahato RI: Novel branched poly(ethylenimine)cholesterol water-soluble lipopolymers for gene delivery. Biomacromolecules 2002;3:1197-1207.

-16 Rejman J, Bragonzi A, Conese M: Role of clathrin- and caveolae-mediated endocytosis in gene transfer mediated by lipo- and polyplexes. Mol Ther 2005;12:468-474.

17 Wang LH, Rothberg KG, Anderson RG: Mis-assembly of clathrin lattices on endosomes reveals a regulatory switch for coated pit formation. J Cell Biol 1993;123:1107-1117.

-18 Kanatani I, Ikai T, Okazaki A, Jo J, Yamamoto M, Imamura M, Kanematsu A, Yamamoto S, Ito N, Ogawa O, Tabata Y: Efficient gene transfer by pullulan-spermine occurs through both clathrin- and raft/caveolaedependent mechanisms. J Control Release 2006;116:75-82.

19 Manunta M, Tan PH, Sagoo P, Kashefi K, George AJ: Gene delivery by dendrimers operates via a cholesterol dependent pathway. Nucleic Acids Res 2004;32:2730-2739.

20 S SP, M RR: Redox sensitive cationic pullulan for efficient gene transfection and drug retention in C6 glioma cells. Int J Pharm 2017;530:401-414.

21 Kubota N, Tatsumoto N, Sano T, Toya K: A simple preparation of half N-acetylated chitosan highly soluble in water and aqueous organic solvents. Carbohydr Res 2000;324:268-274.

-22 Ishikawa H, Jo J, Tabata Y: Liver Anti-Fibrosis Therapy with Mesenchymal Stem Cells Secreting Hepatocyte Growth Factor. J Biomater Sci Polym Ed 2012;23:2259-2272.

-23 Bieber T, Meissner W, Kostin S, Niemann A, Elsasser HP: Intracellular route and transcriptional competence of polyethylenimine-DNA complexes. J Control Release 2002;82:441-454.

24 Baglio SR, Pegtel DM, Baldini N: Mesenchymal stem cell secreted vesicles provide novel opportunities in (stem) cell-free therapy. Front Physiol 2012;3:359.

25 Li W, Zhao L, Wei T, Zhao Y, Chen C: The inhibition of death receptor mediated apoptosis through lysosome stabilization following internalization of carboxyfullerene nanoparticles. Biomaterials 2011;32:4030-4041.

26 Feng M, Lee D, Li P: Intracellular uptake and release of poly(ethyleneimine)-co-poly(methyl methacrylate) nanoparticle/pDNA complexes for gene delivery. Int J Pharm 2006;311:209-214.

27 Hashimoto M, Morimoto M, Saimoto H, Shigemasa Y, Sato T: Lactosylated chitosan for DNA delivery into hepatocytes: the effect of lactosylation on the physicochemical properties and intracellular trafficking of pDNA/chitosan complexes. Bioconjug Chem 2006;17:309-316.

-28 Imelli N, Meier 0, Boucke K, Hemmi S, Greber UF: Cholesterol is required for endocytosis and endosomal escape of adenovirus type 2. J Virol 2004;78:3089-3098.

29 Conner SD, Schmid SL: Regulated portals of entry into the cell. Nature 2003;422:37-44. 


\section{Cellular Physiology Cell Physiol Biochem 2018;50:1255-1269 \begin{tabular}{l|l|l} 
and Biochemistry & $\begin{array}{l}\text { DOI: 10.1159/000494585 } \\
\text { Published online: 25 October } 2018\end{array}$ & $\begin{array}{l}\text { C) } 2018 \text { The Author(s). Published by S. Karger AG, Basel } \\
\text { www.karger.com/cpb }\end{array}$
\end{tabular}}

Liu et al.: Gene Delivery to Mesenchymal Stem Cells by Lower-Molecular-Weight

Chitosan-Treated Polyethyleneimine

-30 Farhood H, Bottega R, Epand RM, Huang L: Effect of cationic cholesterol derivatives on gene transfer and protein kinase C activity. Biochim Biophys Acta 1992;1111:239-246.

-31 Zhang XQ Wang XL, Zhang PC, Liu ZL, Zhuo RX, Mao HQ, Leong KW: Galactosylated ternary DNA/ polyphosphoramidate nanoparticles mediate high gene transfection efficiency in hepatocytes. J Control Release 2005;102:749-763.

-32 Fischer D, Bieber T, Li Y, Elsasser HP, Kissel T: A novel non-viral vector for DNA delivery based on low molecular weight, branched polyethylenimine: effect of molecular weight on transfection efficiency and cytotoxicity. Pharm Res 1999;16:1273-1279.

-33 Kunath K, von Harpe A, Fischer D, Kissel T: Galactose-PEI-DNA complexes for targeted gene delivery: degree of substitution affects complex size and transfection efficiency. J Control Release 2003;88:159-172. MacRae CA, Peterson RT: Zebrafish as tools for drug discovery. Nat Rev Drug Discov 2015;14:721-731. Howe K, Clark MD, Torroja CF, Torrance J, Berthelot C, Muffato M, Collins JE, Humphray S, McLaren K, Matthews L, McLaren S, Sealy I, Caccamo M, Churcher C, Scott C, Barrett JC, Koch R, Rauch GJ, White S, Chow $\mathrm{W}$ et al.: The zebrafish reference genome sequence and its relationship to the human genome. Nature 2013;496:498-503.

-36 Zon LI, Peterson RT: In vivo drug discovery in the zebrafish. Nat Rev Drug Discov 2005;4:35-44.

37 McGrath P, Li CQ: Zebrafish: a predictive model for assessing drug-induced toxicity. Drug Discov Today 2008;13:394-401.

-38 Evensen L, Johansen PL, Koster G, Zhu K, Herfindal L, Speth M, Fenaroli F, Hildahl J, Bagherifam S, Tulotta C, Prasmickaite L, Maelandsmo GM, Snaar-Jagalska E, Griffiths G: Zebrafish as a model system for characterization of nanoparticles against cancer. Nanoscale 2016;8:862-877.

-39 Fako VE, Furgeson DY: Zebrafish as a correlative and predictive model for assessing biomaterial nanotoxicity. Adv Drug Deliv Rev 2009;61:478-486.

$>40$ Fenaroli F, Westmoreland D, Benjaminsen J, Kolstad T, Skjeldal FM, Meijer AH, van der Vaart M, Ulanova L, Roos N, Nystrom B, Hildahl J, Griffiths G: Nanoparticles as drug delivery system against tuberculosis in zebrafish embryos: direct visualization and treatment. ACS Nano 2014;8:7014-7026.

-41 Wu HM, Pan SR, Chen MW, Wu Y, Wang C, Wen YT, Zeng X, Wu CB: A serum-resistant polyamidoaminebased polypeptide dendrimer for gene transfection. Biomaterials 2011;32:1619-1634.

42 Kilian KA, Bugarija B, Lahn BT, Mrksich M: Geometric cues for directing the differentiation of mesenchymal stem cells. Proc Natl Acad Sci U S A 2010;107:4872-4877.

43 Tachi K, Takami M, Sato H, Mochizuki A, Zhao B, Miyamoto Y, Tsukasaki H, Inoue T, Shintani S, Koike T, Honda Y, Suzuki O, Baba K, Kamijo R: Enhancement of bone morphogenetic protein-2-induced ectopic bone formation by transforming growth factor-beta1. Tissue Eng Part A 2011;17:597-606.

44 Horuk R: Chemokines beyond inflammation. Nature 1998;393:524-525.

45 Bowie MB, McKnight KD, Kent DG, McCaffrey L, Hoodless PA, Eaves CJ: Hematopoietic stem cells proliferate until after birth and show a reversible phase-specific engraftment defect. J Clin Invest 2006;116:28082816.

-46 Wojakowski W, Tendera M, Michalowska A, Majka M, Kucia M, Maslankiewicz K, Wyderka R, Ochala A, Ratajczak MZ: Mobilization of CD34/CXCR4+, CD34/CD117+, c-met+stem cells, and mononuclear cells expressing early cardiac, muscle, and endothelial markers into peripheral blood in patients with acute myocardial infarction. Circulation 2004;110:3213-3220.

47 Yu X, Chen D, Zhang Y, Wu X, Huang Z, Zhou H, Zhang Y, Zhang Z: Overexpression of CXCR4 in mesenchymal stem cells promotes migration, neuroprotection and angiogenesis in a rat model of stroke. J Neurol Sci 2012;316:141-149.

48 Cheng Z, Ou L, Zhou X, Li F, Jia X, Zhang Y, Liu X, Li Y, Ward CA, Melo LG, Kong D: Targeted migration of mesenchymal stem cells modified with CXCR4 gene to infarcted myocardium improves cardiac performance. Mol Ther 2008;16:571-579. 